\title{
The Curvilinear Effect of BMI on Functional Health - Evidence of the Long-Running German Ageing Survey
}

\author{
André Hajek Hans-Helmut König \\ Department of Health Economics and Health Services Research, Hamburg Center for Health \\ Economics, University Medical Center Hamburg-Eppendorf, Hamburg, Germany
}

\section{Keywords}

Functional health $\cdot$ BMI $\cdot$ Curvilinear effect $\cdot$ Physical functioning $\cdot$ Longitudinal study

\begin{abstract}
Aims: We aimed at determining the effect of BMI on functional health among older Germans longitudinally. Methods: Data from four waves (2002-2014) of the German Ageing Survey ('Deutscher Alterssurvey'; DEAS), a representative sample of community-dwelling individuals aged 40 years and above, were used. Functional health was quantified by the subscale 'physical functioning' of the 36-Item Short Form Health Survey (SF-36). Fixed effects regressions were used to estimate the predictors of functional health. Linear, quadratic, and cubic terms were included for BMI (self-reported). Results: Fixed effects regressions showed significant linear, quadratic, and cubic effects of BMI on functional health in the total sample and in both sexes. Furthermore, regressions revealed that functional health decreased with increasing age in the total sample and in both sexes. In addition, changes in marital and employment status were significantly associated with changes in functional health in men, but not in women. Conclusion: Our data indicate that the greater the extreme of BMI (either higher or lower), the greater the risk for functional decline. Nutrition programs aimed at preventing changes to extreme BMI might be productive.

(C) 2017 The Author(s)

Published by S. Karger GmbH, Freiburg
\end{abstract}

\section{Introduction}

It is well known that the BMI is associated with several adverse health outcomes and increased mortality [1]. BMI is also known to be one of the main risk factors for functional health that deserves further attention [2,3]. A large number of cross-sectional studies have shown that BMI is associated with functional health. However, thus far, longitudinal studies 
investigating the effect of BMI on functional health are rare [4-6]. Nevertheless, longitudinal studies are needed to get insights into the causal relationship between BMI and functional health. It is important to know the risk factors that are potentially modifiable in order to minimize the societal burden associated with decreased functional health. Thus, this knowledge is important to develop interventions.

Furthermore, the pattern of the relationship between BMI and functional health is not well understood. For instance, as we lose or increase weight in mid or high age do we gain or lose functional health? If there is a relationship, is it linear or curvilinear (according to the so-called obesity paradox)? This study attempts to clarify the manner in which BMI affects functional health over time. To accomplish this aim, data from a population-based (communitydwelling individuals aged 40 and above) longitudinal study in Germany from 2002 to 2014 was used. We hypothesize that the greater the extreme of BMI (either higher or lower), the greater the risk for losses in functional health. Moreover, we explore whether or not the association between BMI and functional health varies by gender.

\section{Material and Methods}

\section{Sample}

We used data from the public release of the German Ageing Survey ('Deutscher Alterssurvey'; DEAS). This dataset is provided by the Research Data Center of the German Center of Gerontology ('Deutsches Zentrum für Altersfragen'; DZA). It is a large, population-based (national probability sampling) cohort among community-dwelling individuals aged 40 years and above in Germany. These individuals were interviewed by trained staff using standardized questionnaires. Because functional health was assessed from wave 2 (2002) onwards, we focused on the waves 2-5 (2014).

5,194 subjects were interviewed in the second wave, 8,200 subjects in the third wave (2008), and 4,855 subjects in the fourth wave (2011). In addition, 10,325 individuals took part in the fifth wave. For example, the discrepancies regarding the sample size is due to the introduction of a new sample in the third wave $(6,205$ individuals were interviewed for the first time, and 1,995 had already been interviewed in previous waves), whereas all participants from the fourth wave had already been interviewed in former waves. For the first time, 6,002 participants were interviewed in the fifth wave, whereas 4,323 subjects have already been interviewed in former waves. Further details concerning the composition of the sample and the sampling frame were given elsewhere [7]. The study was conducted according to the principles expressed in the Declaration of Helsinki. Prior to the interview, written informed consent was given. All individuals received a small incentive for participation.

\section{Dependent Variable}

Functional health was measured by the subscale 'physical functioning' of the well-established 36-Item Short Form Health Survey (SF-36) [8]. Individuals rated impairments in ten activities of daily living (e.g., bathing, climbing stairs, dressing, or carrying shopping bags) on a three-point scale (from 1 = severely limited to $3=$ not limited at all) [9]. Hence, this study focusses on rather simple activities of daily living. The items were transformed into a scale which ranges from 0 to 100, with higher values reflecting less impairment. The scale has very good psychometric properties [10].

\section{Independent Variables}

BMI (linear, quadratic, and cubic terms) was calculated from self-reported height (meter) and weight $(\mathrm{kg})$ as weight divided by height squared. Besides, we controlled for several time-dependent independent variables which are assumed to be important for functional health. Consequently, we controlled for age, family status (married, living together with spouse (reference); married, living separated from spouse; divorced; widowed; never married), employment status (working (reference); retired; other: not employed), the number of important people in regular contact (ranging between 0 and 9), and comorbidity (total number of illnesses, e.g. diabetes, cancer, bladder problems, bad circulation, insomnia, or hearing problems). Solely for descriptive purposes, the time-constant variables sex and education (educational level, ISCED-97 (International Standard Classification of Education) [11], with low (0-2), medium (3-4), and high (5-6)) was used. 
Hajek and König: The Curvilinear Effect of BMI on Functional Health - Evidence of the Long-Running German Ageing Survey

In sensitivity analysis, the average number of different medications per day was used. However, this was only quantified from wave 3 (2008) onwards. Therefore, our sensitivity analysis focused on the waves 3, 4, and 5.

\section{Statistical Analysis}

Previous longitudinal studies with similar outcome variables showed that it is important to take timeconstant unobserved factors such as genetic disposition into consideration in order to get unbiased estimates $[12,13]$. While pooled ordinary least squares (OLS) regressions only provide consistent estimates under the absence of time-constant unobserved factors, random effects (RE) strategies provide consistent estimates even if time-constant unobserved factors exist. However, RE regression techniques only provide consistent estimates when these time-constant unobserved factors are not systematically correlated with the predictors. Actually, this is a very strong assumption which is often violated [12,13]. Consequently, FE regressions were used since they provide consistent estimates (under the assumption of strict exogeneity) even if timeconstant unobserved factors are correlated with the predictors [14].

Contrarily to RE regressions which take between- and within-information into consideration, fixedeffects (FE) regressions only take intra-individual changes (within-information) into account. Hence, the FE estimator is also called 'within-estimator'. Consequently, time-constant factors (unobserved and observed) are taken into consideration. The FE estimator eliminates the time-constant component of the error (so called 'fixed effects'). This means that bias resulting from genetic differences between individuals, a potential confounder that is nearly impossible to measure in large surveys, is not a problem when using FE regressions. Please see Wooldridge [15] or Cameron and Trivedi [14] for technical details and further assumptions.

\section{Results}

\section{Sample Characteristics}

As our interest lies in changes within individuals over time, individuals were included in FE regression analysis, if they had changes in functional health between 2002 and 2014 (resulting in a sample size of 21,692 observations to be examined). Descriptive statistics for subjects included in FE regression analysis are displayed in table 1.

As for gender (which was not included in FE regressions because it is a time-constant independent variable), $50.9 \%$ were male. The mean age was $63.5 \pm 11.5$ years (ranging from 40 to 95 years). $52.7 \%$ of the individuals had a medium education, and $52.9 \%$ of the individuals were retired. The mean number of important people in regular contact was $4.9 \pm 2.7$. The mean number of chronic diseases was $2.4 \pm 1$.9. Furthermore, the mean BMI was $26.7 \pm$ $4.5 \mathrm{~kg} / \mathrm{m}^{2}$, and the mean functional health was $83.0 \pm 22.7$.

\section{Correlations}

Pairwise cross-sectional Pearson correlations were displayed in table 2 to get a deeper understanding of our data.

Functional health was significantly associated with BMI $(r=-0.20, p<0.001)$. Furthermore, functional health was significantly associated with age $(\mathrm{r}=-0.35, \mathrm{p}<0.001)$, marital status $(\mathrm{r}$ $=-0.11, \mathrm{p}<0.001)$, being retired $(\mathrm{r}=-0.30, \mathrm{p}<0.001)$, the number of important people in regular contact $(r=0.08, p<0.001)$, and the number of chronic diseases $(r=-0.45, p<0.001)$.

\section{Main Analysis}

When adjusting for potential confounders, linear FE regressions (table 3) revealed that functional health increased with BMI in the total sample and in both sexes (columns 1, 4 and 7). In the total sample and in women (columns 2 and 8), functional health increased with linear and quadratic BMI, whereas functional health did not increase with linear and quadratic BMI in men (column 5). However, linear, quadratic, and cubic BMI terms were significantly associated with changes in functional health in the total sample and in both sexes (columns 
Table 1. Sample characteristics for individuals included in fixed effects regressions (2002-2014, pooled)

Male: N (\%)

Education

Low (ISCED-97: 0-2), N (\%)

Medium (ISCED-97: 3-4), N (\%)

High (ISCED-97: 5-6), N (\%)

Age, mean (SD), range, years

Married, living together with spouse, N (\%)

Employment status

Working, N (\%)

Retired: N (\%)

Other: $\mathrm{N}(\%)$

Number of important people in regular contact, mean (SD), range

Number of chronic diseases, mean (SD), range

$\mathrm{BMI}$, mean (SD), range, $\mathrm{kg} / \mathrm{m}^{2}$

Functional health (subscale 'physical functioning' of the SF-36), mean (SD), range

Observations
$11,041(50.9)$

$1,475(9.7)$

$8,036(52.7)$

5,727 (37.6)

63.5 (11.5), 40-95

15,568 (71.8)

$7,735(35.7)$

11,476 (52.9)

2,481 (11.4)

4.9 (2.7), 0-9

2.4 (1.9), $0-11$

26.7 (4.5), 14.8-94.6

83.0 (22.7), 0-100

21,692

Table 2. Pairwise cross-sectional correlations (with Bonferroni correction for multiple comparisons; 2002-2014, pooled)

\begin{tabular}{|c|c|c|c|c|c|c|c|c|}
\hline & $\begin{array}{l}\text { Functional } \\
\text { health (subscale } \\
\text { 'physical functioning' } \\
\text { of the SF-36) }\end{array}$ & Age & $\begin{array}{l}\text { Marital status } \\
\text { (ref.: married, } \\
\text { living together } \\
\text { with spouse) }\end{array}$ & $\begin{array}{l}\text { Employment } \\
\text { status: retired } \\
\text { (ref.: working) }\end{array}$ & $\begin{array}{l}\text { Employment } \\
\text { status: other }\end{array}$ & $\begin{array}{l}\text { Number of } \\
\text { important } \\
\text { people in } \\
\text { regular contact }\end{array}$ & $\begin{array}{l}\text { Number } \\
\text { of chronic } \\
\text { diseases }\end{array}$ & BMI \\
\hline $\begin{array}{l}\text { Functional health } \\
\text { (subscale 'physical } \\
\text { functioning' of the SF-36) }\end{array}$ & 1 & & & & & & & \\
\hline Age & $-0.347^{* * *}$ & 1 & & & & & & \\
\hline $\begin{array}{l}\text { Marital status (ref.: } \\
\text { married, living } \\
\text { together with spouse) }\end{array}$ & $-0.114^{* * *}$ & $0.0735^{* * *}$ & 1 & & & & & \\
\hline $\begin{array}{l}\text { Employment status: } \\
\text { retired (ref.: working) }\end{array}$ & $-0.296^{* * *}$ & $0.771^{* * *}$ & $0.0489^{* * *}$ & 1 & & & & \\
\hline Employment status: other & r 0.00972 & $-0.156^{* * *}$ & 0.00244 & $-0.381^{* * *}$ & 1 & & & \\
\hline $\begin{array}{l}\text { Number of important } \\
\text { people in regular contact }\end{array}$ & $0.0792^{* * *}$ & $-0.106^{* * *}$ & $-0.114^{* * *}$ & $-0.0782^{* * *}$ & -0.0146 & 1 & & \\
\hline $\begin{array}{l}\text { Number of chronic } \\
\text { diseases }\end{array}$ & $-0.451^{* * *}$ & $0.371^{* * *}$ & $0.0655^{* * *}$ & $0.309^{* * *}$ & $-0.0409^{* * *}$ & -0.0127 & 1 & \\
\hline BMI & $-0.202^{* * *}$ & $0.0402^{* * *}$ & $-0.0210^{+}$ & $0.0611^{* * *}$ & 0.00782 & -0.0118 & $0.184^{* * *}$ & 1 \\
\hline Observations & 21,692 & & & & & & & \\
\hline
\end{tabular}

3, 6 and 9). The interaction terms $\left(\mathrm{BMI} \times \mathrm{sex}, \mathrm{BMI}^{2} \times \mathrm{sex}, \mathrm{BMI}^{3} \times \mathrm{sex}\right)$ were all not significant (not shown). Our analysis is graphically illustrated by using the 'marginsplot' command in Stata (fig. 1). The curve shows a steep incline in functional health (e.g., from BMI of $15 \mathrm{~kg} / \mathrm{m}^{2}$ to BMI of $23 \mathrm{~kg} / \mathrm{m}^{2}$ ) with a subsequent flattening slope until excess weight. After that, the slope declines more steeply.

Furthermore, functional health decreased with increasing age in the total sample and in both sexes. In addition, while changes in marital and employment status were significantly associated with changes in functional health in men, changes in marital and employment status were not significantly associated with changes in functional health in women. 
Hajek and König: The Curvilinear Effect of BMI on Functional Health - Evidence of the Long-Running German Ageing Survey

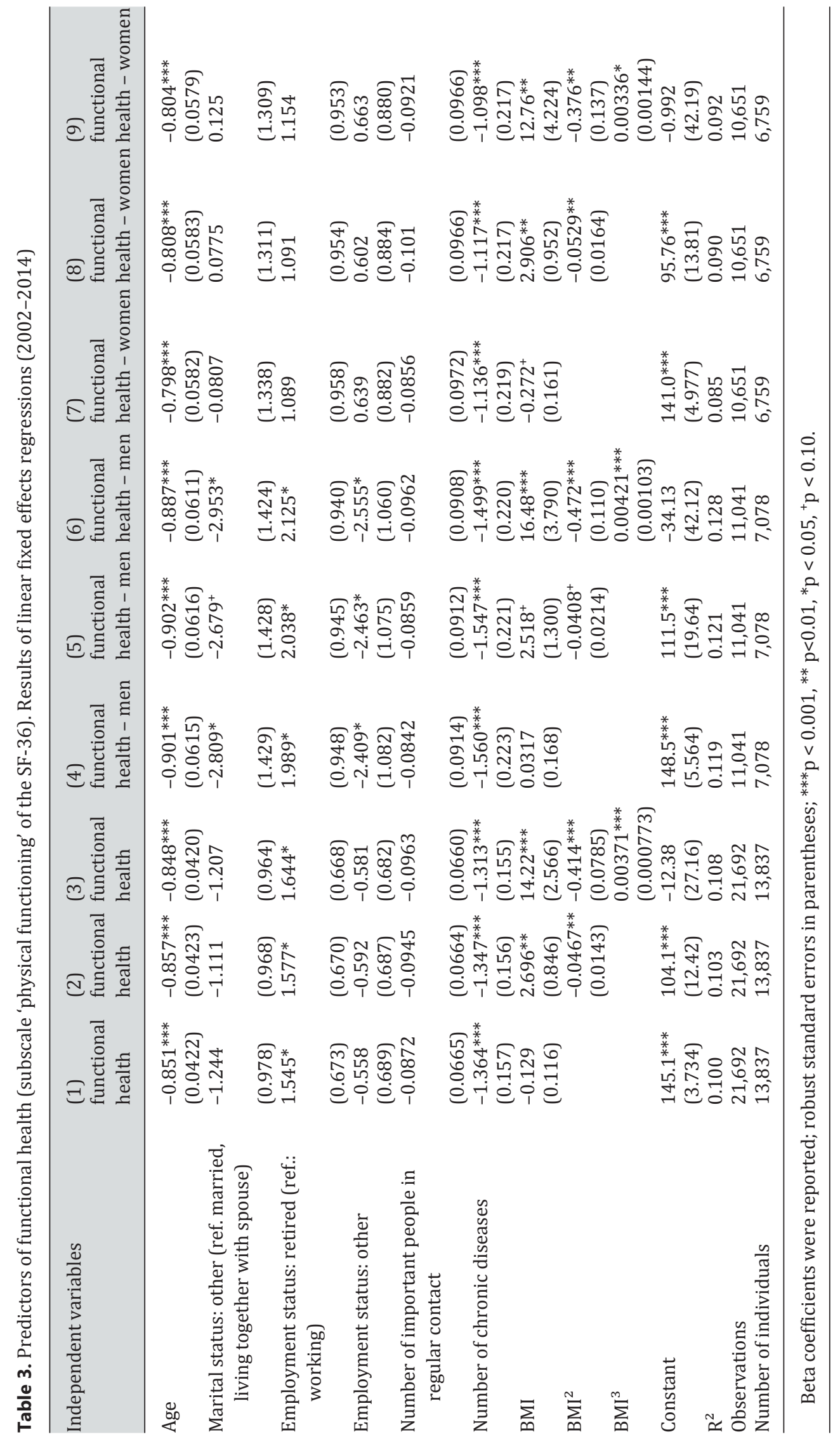


Fig. 1. Margins-Plot for the relation between BMI and functional health (subscale 'physical functioning' of the SF-36). Predictive margins with 95\% CIs are displayed.

Hajek and König: The Curvilinear Effect of BMI on Functional Health - Evidence of the Long-Running German Ageing Survey

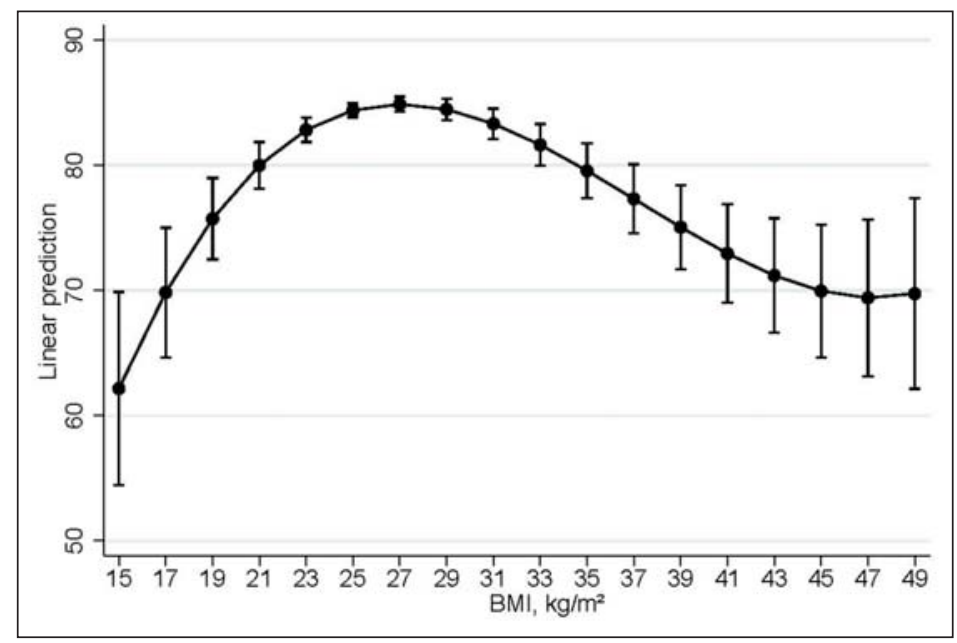

In the sensitivity analysis (results not shown, but available upon request), the main model was extended by adding the average number of different medications per day. However, it is worth repeating that this variable was only quantified from wave 3 onwards. Consequently, our sensitivity analysis only used data from the waves 3,4 , and 5 . In terms of effect sizes and significance, findings remained almost the same. However, in women, the cubic term $\left(\mathrm{BMI}^{3}\right)$ lost significance $(\mathrm{p}<0.10)$.

\section{Discussion}

\section{Main Findings}

By using data from a population-based sample of individuals aged 40 and above in Germany, this study attempted to clarify the manner in which BMI affects functional health over time. FE regressions revealed a curvilinear effect of BMI on functional health in the total sample and in both sexes, with non-significant gender differences. In sum, the greater the extreme of BMI (either higher or lower), the greater the risk for functional decline.

\section{Previous Research}

While numerous cross-sectional studies found positive associations between BMI and functional health in older adults [16, 17], only a few population-based longitudinal studies investigated the effect of BMI on functional health. For instance, by using data from a prospective cohort study (Australian Longitudinal Study of Ageing, 1992-1994), Bannerman et al. [18] showed that a loss of $10 \%$ body weight significantly increased the risk of functional limitations in individuals aged 70 and above. Moreover, also by using data from a prospective cohort study (population-based National Health and Nutrition Examination Survey I, 19711987), Launer et al. [19] found that a weight loss of more than $5 \%$ was associated with an increase in mobility disability in very old women (mean age 76 years at baseline). Mobility disability was quantified as report of any difficulty in at least one of several activities (e.g., climbing two steps, carrying a full bag of groceries, doing heavy chores, or bending to the floor). Moreover, Arnold et al. [20], Jensen et al. [21], Lee et al. [22], and Artaud et al. [4] could also show that an increased BMI as well as weight losses are associated with a greater risk of functional decline or physical functioning. 
Hajek and König: The Curvilinear Effect of BMI on Functional Health - Evidence of the Long-Running German Ageing Survey

Previous longitudinal studies in several countries found that underweight led to functional impairment $[16,18,23,24]$. In total, these findings correspond to our results and might be explained by a lack of physical activity and a higher risk of falls [25] which in turn might lead to decreased functional health.

As for the nature of the relationship between BMI and functional health, some studies investigating the effect of BMI on functional health have included BMI as a continuous predictor (assuming a linear relationship) [26], whereas other longitudinal studies have shown that the relationship between BMI and functional health is curvilinear. Consequently, longitudinal studies exist using gender-specific BMI tertiles [19], quartiles [27], quintiles [24], or other classifications [23]. For example, LaCroix et al. [24] found that high compared with moderate BMI was associated with an increased risk of losing mobility, whereas low BMI was not associated with the risk of losing mobility. Similar findings were reported by Harris et al. [27]. They found that continued physical ability was associated with a BMI less than the 75 th percentile which equals BMI of about $25 \mathrm{~kg} / \mathrm{m}^{2}$ compared with a BMI greater than 75 th percentile. By controlling for unobserved and observed time-constant factors and by integrating linear, quadratic, and cubic terms for BMI, our study extend previous knowledge based on other statistical methods and classifications of BMI categories.

\section{Strengths and Limitations}

This is the first longitudinal study investigating the curvilinear effect of BMI on functional health among older Germans. Moreover, it is worth highlighting that functional health was quantified by using a validated instrument. By using FE regressions, time-constant factors (observed and unobserved) can be taken into consideration, resulting in consistent estimates (under the assumption of strict exogeneity). Additionally, by using panel data methods, insights into the causal mechanism can be derived (average treatment effect on the treated) $[28,29]$. However, in contrast to a randomized controlled trial, the current observational study, which used self-reported data, did not have a controlled treatment. This limits causal inference from our study even though, for linguistic reasons, seemingly causal terminology was occasionally used in our report.

By using a large population-based sample of community-dwelling subjects ( $\geq 40$ years) in Germany, this longitudinal observational study showed that, after adjusting for various important time-varying potential confounders, decreases from very high BMI values (e.g., 40 $\mathrm{kg} / \mathrm{m}^{2}$ ) to high BMI values (e.g., $35 \mathrm{~kg} / \mathrm{m}^{2}$ ) within an individual were associated with increases in functional health within an individual over time. This might give first insights into the causal relationship between BMI and functional health (with limitations noted above). However, randomized controlled trials are necessary to confirm the present findings.

One limitation is that only self-reported data were available concerning height and weight. Thus, it is assumed that BMI is biased downwards since individuals tend to overestimate height and underestimate weight [30]. However, when this downwards bias is constant within individuals over time, it does not bias FE estimates (please see 'Statistical Analysis' above for further details).

Besides, the influence of fat and muscle mass cannot be assessed for reasons of data availability. Additionally, it is assumed that our estimates are downward biased for reasons of panel attrition [31]. Moreover, we cannot rule out that reverse causality exists (e.g., functional health affecting BMI). However, dealing with this bias requires even more complex regression techniques (e.g., the use of so-called 'panel instrumental variable approaches' [32]). An instrumental variable is a factor that is associated with an independent variable suspected of being endogenous (here: own BMI) and is only associated with the outcome measure (here: functional health) because of its relation with the risk factor of interest (here: own BMI). For an empirical example, please see Smith et al. [33]. These approaches, however, depend on very 
strong assumptions, and strong instruments are difficult to identify. Therefore, FE regressions were used in the present study, which can mitigate the problem of unobserved heterogeneity - a main problem in cross-sectional observational studies [28].

\section{Conclusion}

The results of this study suggest that the effect of BMI on functional health in older adults is complex. One can conclude that nutrition programs aimed at preventing changes to extreme BMI may be productive. However, it might be difficult to change lifestyle behavior (weight management) in older adults [34]. Consequently, in order to be effective, such programs must be tailored to address the needs of older adults [35]. This is vital as losses in functional health are in turn related to adverse outcomes, including admission to nursing home [36] or frailty [37].

\section{Disclosure Statement}

The authors declared that there are no conflicts of interest.

\section{References}

1 Calle EE, Thun MJ, Petrelli JM, Rodriguez C, Heath CW: Body-mass index and mortality in a prospective cohort of U.S. adults. N Engl J Med 1999;341:1097-1105.

2 Friedmann JM, Elasy T, Jensen GL: The relationship between body mass index and self-reported functional limitation among older adults: a gender difference. J Am Geriatr Soc 2001;49:398-403.

3 Stuck AE, Walthert JM, Nikolaus T, Büla CJ, Hohmann C, Beck JC: Risk factors for functional status decline in community-living elderly people: a systematic literature review. Soc Sci Med 1999;48:445-469.

4 Artaud F, Singh-Manoux A, Dugravot A, Tavernier B, Tzourio C, Elbaz A: Body mass index trajectories and functional decline in older adults: Three-City Dijon Cohort Study. Eur J Epidemiol 2016;31:73-83.

5 Beavers KM, Beavers DP, Houston DK, Harris TB, Hue TF, Koster A, Newman AB, Simonsick EM, Studenski SA, Nicklas BJ: Associations between body composition and gait-speed decline: results from the Health, Aging, and Body Composition study. Am J Clin Nutr 2013;97:552-560.

6 Forrest KY, Zmuda JM, Cauley JA: Correlates of decline in lower extremity performance in older women: a 10-year follow-up study. J Gerontol A Biol Sci Med Sci 2006;61:1194-1200.

7 Klaus D, Engstler H: Daten und Methoden des Deutschen Alterssurveys; in Mahne K, Wolff JK, Simonson J, Tesch-Römer C (eds): Altern im Wandel: Zwei Jahrzehnte Deutscher Alterssurvey (DEAS). Berlin, Springer VS, 2016, pp 25-42.

8 Ware JE Jr, Sherbourne CD: The MOS 36-item short-form health survey (SF-36): I. Conceptual framework and item selection. Med Care 1992:473-483.

9 Bullinger M, Kirchberger I: Fragebogen zum Gesundheitszustand. Handanweisung. Göttingen, Hogrefe, 1998.

10 Warner LM, Schwarzer R, Schüz B, Wurm S, Tesch-Römer C: Health-specific optimism mediates between objective and perceived physical functioning in older adults. J Behav Med 2012;35:400-406.

11 UNESCO (ed): International Standard Classification of Education. ISCED 1997. Re-edition. Paris, UNESCO-UIS, 2006. www.uis.unesco.org/Library/Documents/isced97-en.pdf (last accessed May 29, 2017).

12 Alva M, Gray A, Mihaylova B, Clarke P: The effect of diabetes complications on health-related quality of life: the importance of longitudinal data to address patient heterogeneity. Health Econ 2014;23:487-500.

13 Eisele M, Kaduszkiewicz H, König H-H, Lange C, Wiese B, Prokein J, Weyerer S, Werle J, Riedel-Heller SG, Luppa M: Determinants of health-related quality of life in older primary care patients: results of the longitudinal observational AgeCoDe study. Br J Gen Pract 2015;65:e716-e723.

14 Cameron AC, Trivedi PK: Microeconometrics: Methods and Applications. New York, Cambridge University Press, 2005.

15 Wooldridge JM: Econometric Analysis of Cross Section and Panel Data. Cambridge, MIT Press, 2010.

16 Davison KK, Ford ES, Cogswell ME, Dietz WH: Percentage of body fat and body mass index are associated with mobility limitations in people aged 70 and older from NHANES III. J Am Geriatr Soc 2002;50:1802-1809.

17 Neumann L, Lerner E, Glazer Y, Bolotin A, Shefer A, Buskila D: A cross-sectional study of the relationship between body mass index and clinical characteristics, tenderness measures, quality of life, and physical functioning in fibromyalgia patients. Clin Rheumatol 2008;27:1543-1547. 
Hajek and König: The Curvilinear Effect of BMI on Functional Health - Evidence of the Long-Running German Ageing Survey

18 Bannerman E, Miller MD, Daniels LA, Cobiac L, Giles LC, Whitehead C, Andrews GR, Crotty M: Anthropometric indices predict physical function and mobility in older Australians: the Australian Longitudinal Study of Ageing. Public Health Nutr 2002;5:655-662.

19 Launer LJ, Harris T, Rumpel C, Madans J: Body mass index, weight change, and risk of mobility disability in middle-aged and older women: the epidemiologic follow-up study of NHANES I. JAMA 1994;271:1093-1098.

20 Nakhaie R, Arnold R: A four year (1996-2000) analysis of social capital and health status of Canadians: The difference that love makes. Soc Sci Med 2010;71:1037-1044.

21 Jensen GL, Friedmann JM: Obesity is associated with functional decline in community-dwelling rural older persons. J Am Geriatr Soc 2002;50:918-923.

22 Lee JS, Kritchevsky SB, Tylavsky F, Harris T, Simonsick EM, Rubin SM, Newman AB: Weight change, weight change intention, and the incidence of mobility limitation in well-functioning community-dwelling older adults. J Gerontol A Biol Sci Med Sci 2005;60:1007-1012.

23 Guralnik JM, Kaplan GA: Predictors of healthy aging: prospective evidence from the Alameda County study. Am J Public Health 1989; 79:703-708.

24 LaCroix AZ, Guralnik JM, Berkman LF, Wallace RB, Satterfield S: Maintaining mobility in late life. II. Smoking, alcohol consumption, physical activity, and body mass index. Am J Epidemiol 1993;137:858-869.

25 Larrieu S, Peres K, Letenneur L, Berr C, Dartigues J, Ritchie K, Fevrier B, Alperovitch A, Barberger-Gateau P: Relationship between body mass index and different domains of disability in older persons: the 3C study. Int J Obes 2004;28:1555-1560.

26 Seeman TE, Charpentier PA, Berkman LF, Tinetti ME, Guralnik JM, Albert M, Blazer D, Rowe JW: Predicting changes in physical performance in a high-functioning elderly cohort: MacArthur studies of successful aging. J Gerontol 1994;49:M97-M108.

27 Harris T, Kovar MG, Suzman R, Kleinman JC, Feldman JJ: Longitudinal study of physical ability in the oldest-old. Am J Public Health 1989; 79:698-702.

28 Brüderl J, Ludwig V: Fixed-effects panel regression; in Wolf C (ed): The Sage Handbook of Regression Analysis and Causal Inference. Los Angeles, SAGE, 2015, pp 327-357.

29 Gangl M: Causal inference in sociological research. Annu Rev Sociol 2010;36:21-47.

30 Gorber SC, Tremblay M, Moher D, Gorber B: A comparison of direct vs. self-report measures for assessing height, weight and body mass index: a systematic review. Obes Rev 2007;8:307-326.

31 Schiel S, Dickmann C, Aust F: Methodenbericht Deutscher Alterssurvey (DEAS): 4. Befragungswelle. Panelbefragung 2011. Bonn, infas, 2011,

32 Brüderl J: Kausalanalyse mit Paneldaten; in Wolf C, Best H (eds): Handbuch der sozialwissenschaftlichen Datenanalyse. Wiesbaden, VS-Verlag, 2010, pp 963-994.

33 Smith GD, Sterne JA, Fraser A, Tynelius P, Lawlor DA, Rasmussen F: The association between BMI and mortality using offspring BMI as an indicator of own BMI: large intergenerational mortality study. BMJ 2009;339:b5043.

34 Riegel B, Bennett JA: Cardiovascular disease in elders: is it inevitable? J Adult Dev 2000; 7:101-111.

35 Jensen GL, Roy MA, Buchanan AE, Berg MB: Weight loss intervention for obese older women: improvements in performance and function. Obes Res 2004;12:1814-1820.

36 Hajek A, Brettschneider C, Lange C, Posselt T, Wiese B, Steinmann S, Weyerer S, Werle J, Pentzek M, Fuchs A, Stein J, Luck T, Bickel H, Mösch E, Wagner M, Jessen F, Maier W, Scherer M, Riedel-Heller S, König HH: Longitudinal predictors of institutionalization in old age. PLoS One 2015;10:e144203.

37 Hajek A, Brettschneider C, Posselt T, Lange C, Mamone S, Wiese B, Weyerer S, Werle J, Fuchs A, Pentzek M, Stein J, Luck T, Bickel H, Mösch E, Heser K, Jessen F, Maier W, Scherer M, Riedel-Heller SG, König HH: Predictors of frailty in old age - results of a longitudinal study. J Nutr Health Aging 2016;20:952-957. 